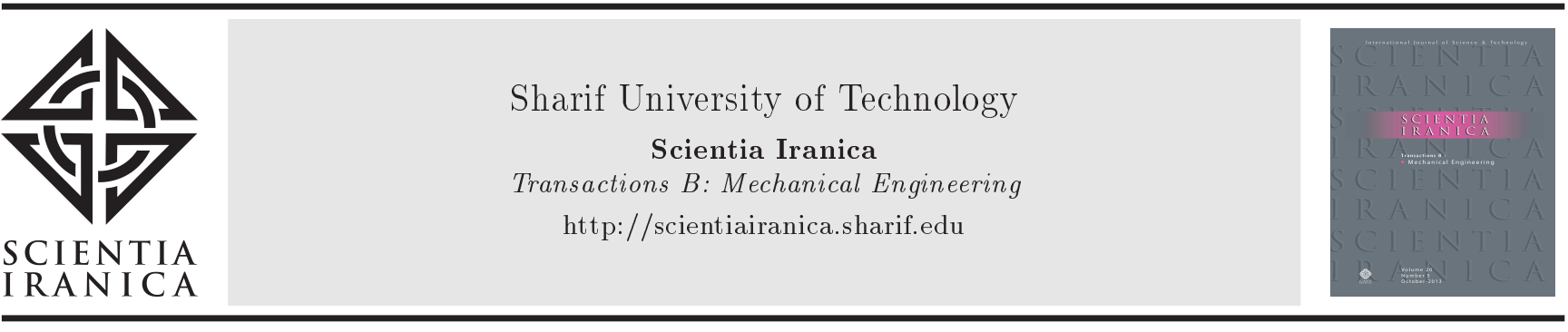

\title{
Ultrasonic bone-cutting: Experimental investigation and statistical analyses of cutting forces
}

\author{
M. Rezaei ${ }^{a, *}$, M. Farzin ${ }^{a}$, M.R. Niroomand ${ }^{\text {b }}$, and F. Ahmadi ${ }^{c}$ \\ a. Department of Mechanical Engineering, Isfahan University of Technology, Isfahan, Iran. \\ b. Department of Mechanical Engineering, Payame Noor University, Tehran, Iran. \\ c. Department of Mechanical Engineering, University of Kashan, Kashan, Iran.
}

Received 17 July 2020; received in revised form 12 November 2020; accepted 13 January 2021

\section{KEYWORDS}

Ultrasonic cutting;

Cortical bone;

Cutting force;

Tool geometry;

Statistical analyses;

Design of experiments.

\begin{abstract}
Low cutting forces can significantly reduce the risk of damage to sensitive tissues adjacent to the bone. Because of its better control of the incision, lower cutting force and reduced postoperative complications, the application of ultrasonic tools in bone-cutting is of concern to surgeons. In this study, through the application of a full factorial design of experiments, the effects of changes in cutting tool geometry, ultrasonic power, bone-cutting direction, and tool speed on the cutting forces of cortical bone are assessed simultaneously. The variance and regression of the experimental data are analyzed, and the impact of factors and interactions of the elements on the cutting forces are discussed. The adjusted coefficient of determination $\left(R_{\mathrm{adj}}^{2}\right)$ of the main cutting force and cutting resistance force of the statistical model were $91.49 \%$ and $91.15 \%$, respectively. Both the blade geometry and ultrasonic power, together with their interactions, are the most influential factors in the cutting forces, contributing $82.2 \%$ and $86.6 \%$, respectively. The formation of teeth in the cutting edge improves the cutting process and reduces the cutting force by about $40 \%$. To obtain high efficiency and low cutting force, it is recommended to use an ultrasonic-powered toothed edge blade with a pitch of $1 \mathrm{~mm}$, a low vertical velocity, and a high longitudinal speed.
\end{abstract}

(C) 2021 Sharif University of Technology. All rights reserved.

\section{Introduction}

Tissue cutting is the term used for the incision of human body biological materials, which include either soft tissues like skin or hard tissues like bone. Although tissue cutting is one of the routine steps in most

*. Corresponding author. Tel.: +983133915218 E-mail addresses: m.rezaei@me.iut.ac.ir (M. Rezaei); farzin@cc.iut.ac.ir (M. Farzin); niroomand@pnu.ac.ir (M.R. Niroomand); fa.ahmadi@kashanu.ac.ir (F. Ahmadi)

doi: $10.24200 /$ sci. 2021.56431 .4720 surgeries, it sometimes becomes important because any damage to the neurovascular system or surrounding living tissues could lead to catastrophic results [1]. Bone-cutting has always been and is a major challenge among surgeons because it requires high skill and accurate tools for a successful operation [2]. Some new tools have been devised that can be applied in bone cutting. These devices are contributing to reducing surgery's harmful effects and better and faster tissue healing [3-5].

Although different commercial devices have been and are being developed for different surgical operations, there still exists a need to design the appropriate 
tools for more precise and deep cuttings. The available blades' profile requires further design modification to decrease the cutting force $[6,7]$.

One of the medical applications of ultrasound is bone-cutting that has several advantages:

1. Minimizes the damage risk to adjacent soft tissues and sensitive structures like vessels, nerves, mucous, etc.;

2. Reduces the force applied to the blade and tissue adhesion to the tool while being controllable by the surgeon;

3. Decrease bleeding and the possibility of generating undesirable bone fracture at the surgical site and shorten the healing process after surgery;

4. The vibrations and noise generated by the ultrasonic instrument's micro-vibrations are low, which can reduce the patient's inconvenience and fear;

5. Alternate contact between ultrasound blade and bone minimizes the possibility of tool breakage in the cutting process [8-12].

Although ultrasound has documented advantages in bone-cutting [13-15] or other surgical procedures $[16,17]$, the advantages of ultrasound in surgery require further research to make it more promising. The capabilities and advantages of different ultrasonic devices are discussed and compared with Parmar et al. [18] and Hollstein et al. [19]. In the available studies, the focus is on the part of the effective parameters like bone drilling force or stress [20-24], temperature [2527], and non-ultrasound tools [28]. Ying et al. [29,30] evaluated the temperature and cutting force in both ultrasonic and non-ultrasonic conditions. They studied the vibration factors influence and the processing parameters with no concern for the effects of other important factors, like changing in blade geometry and cutting directions, and different tool speeds.

Alam et al. [8] showed that the force required to penetrate the tool in bone-cutting is one of the most important factors for surgeons because it can cause essential mechanical harm to the surrounding tissues. To the best of the authors knowledge, no study is run to investigate the influence of different important factors on the bone-cutting forces in a simultaneous manner.

This study aims to provide a comprehensive evaluation of the effect of several tools with different geometries on the cutting forces applied when cutting bones with and without ultrasonic power at different speeds and directions. First, a full factorial Design Of Experiments (DOEs) was implemented; next, analysis of variance (ANOVA) and regression was run. Finally, the main effect and interaction plots were used to evaluate the impact of variables on the response. By simultaneously assessing the different parameters, the impact of various factors on the force applied to the cutting tool was measured. The results of these assessments provide an in-depth understanding of the crucial factors of the ultrasonic cutting technique in bone cutting, which in turn promotes the wide application of the ultrasonic cutting technique in surgical operations.

\section{Methods and material}

The method adopted in this study is experimental.

\subsection{The ultrasonic system}

The ultrasonic system consists of the following parts:

1. A generator with maximum power up to $1000 \mathrm{~W}$ (according to the required power), and a frequency within $10-200 \mathrm{kHz}$ range, which can be configured and selected;

2. A Langevin-type transducer with a resonance frequency of $36 \mathrm{kHz}$.

The horn and back mass of the transducer was made of titanium and stainless steel, respectively. As described by Peng et al. [31], the number of piezoelectric discs must be even to ensure that the first and last piezoelectric discs are connected to the negative pole of the electric circuit. Details of the system designed and built in this project are explained by Rezaei et al. [32].

The blade displacement $(x)$ in ultrasonic mode is $x=A \cdot \sin (2 \pi f t)$, where $A, f$, and $t$ are the amplitude, frequency, and time, respectively [8]. Consequently, the blade acceleration is $a=-4 A \pi^{2} f^{2} \cdot \sin (2 \pi f t)$. According to Newton's second law, $F=m a$ that $F$ and $m$ are force and mass, respectively. According to the results reported by Wang et al., there is a positive correlation between the ultrasonic power and its amplitude [33], and the change of the ultrasonic power supplied by the generator can change the vibration amplitude. To change the magnitude of frequency, the ultrasonic parts, such as transducers, horns, and blades, should be replaced. For any new frequency, a new setup is needed, which is very expensive and time-consuming. Consequently, in this study, the generator power was selected as a variable.

\subsection{Selection of bone}

In this study, a fresh bovine femur was selected for this study because its mechanical properties are similar to human bone [34]. The two ends of the bone (Epiphysis) were cut, and its rod-shaped portion (Diaphysis) that has cortical structure was the subject of the experiments. As stated by Ralston [35], the hard outer and porous inner parts of bones are called cortical (or compact) and cancellous (or trabecular) bone.

Due to the cortical bone anisotropic nature, it has different mechanical properties in different directions [36-39]. Generally, according to [40-42], three 
directions could be defined for the cortical bone: longitudinal or parallel, radial or across, and transverse. One of this study's objectives is to assess the effect of these different directions on ultrasonic cutting forces.

According to the types of cutting tools used in this study and common cutting methods in surgery, only the longitudinal, and transverse directions are considered, Figure 1.

As observed in Figure 1(b), with respect to the bone longitudinal axis, the cortical samples were prepared in the form of a ring and strip. According to the cutting direction in the experiments, the cut specimens were named BCL (Bone-Cutting in the Length direction) and BCW (Bone-Cutting in the Width direction).

\subsection{Blade geometry}

Macbeath et al. [43] reported that the blade geometry is one of the cutting variables, which affects the friction and initial interaction between the ultrasonic tool and the bone and positively affects the cutting quality. Consequently, the geometry of the tool is very important and should be thoroughly studied. According to the results of Ying et al. [30], by coming up with accurate geometry(s) for the blades, the bone incision will be more appropriate depending on the cutting condition manner.

Five blade shapes were applied to assess the blade geometry's effect on the bone-cutting process and the applied forces to them. The blade types in this study consist of:
1. One simple type (the plain cutting edge);

2. One sharp type (with a 30-degree edge angle);

3. Three toothed edge type (with the same tooth depth of $0.75 \mathrm{~mm}$ and different tooth pitches of 0.8 , 1.0 , and $1.2 \mathrm{~mm}$ ).

The blades were prepared with two edges, and one of the presented shapes was created on each edge. Consequently, two double-edge blades and one simple blade were made. Two types of double-edged blades with sharp and toothed edges are shown in Figure 2.

All blades were made of cold work tool steel (Bohler K100) with a thickness of $0.6 \mathrm{~mm}$ and a length of $12 \mathrm{~mm}$, and were equipped with a CNC lathe and a wire cutting machine.

\subsection{Experimental setup}

The blades were inserted into the transducer, and the setup was placed in the fixture from the transducer nodal point (the nodal point is a point where the amplitude of vibration is about zero, so clamping the transducer from this point does not affect the wave transition to the cutting region). This fixture was clamped to the 3 -axis CNC vertical milling machine (FP4ME, Tabriz, Iran) column, Figure 3.

The motion in $Y, \bar{X}$, and $Z$-directions were made with the CNC machine's head and table, respectively. The edge of the cutting blades was tangential to the surface of the bone. Four programs were prepared CNC movement, in which the blade was fixed in the $Y$-direction, and at the same time, reciprocated and

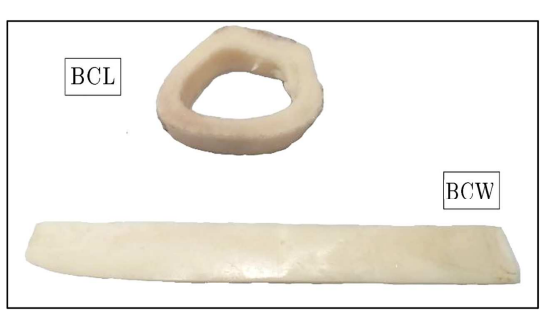

(a)

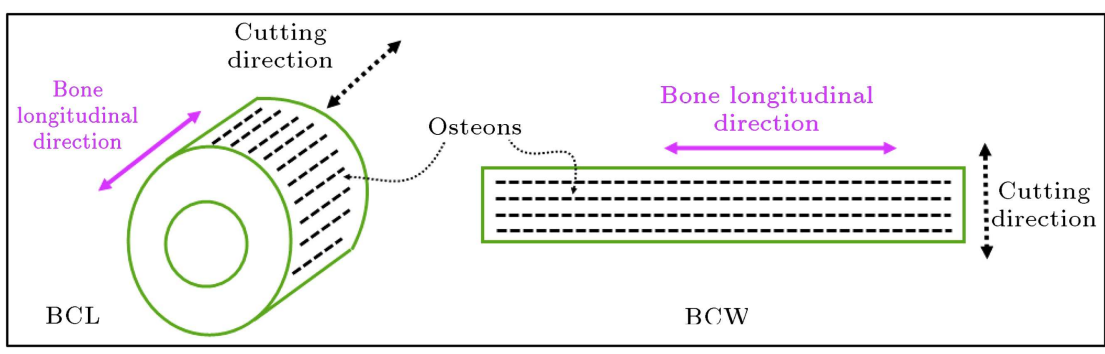

(b)

Figure 1. Samples of cortical bones: (a) Real specimens and (b) schematic views and details.

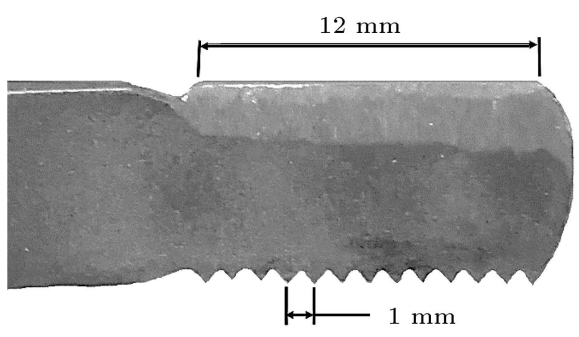

(a)

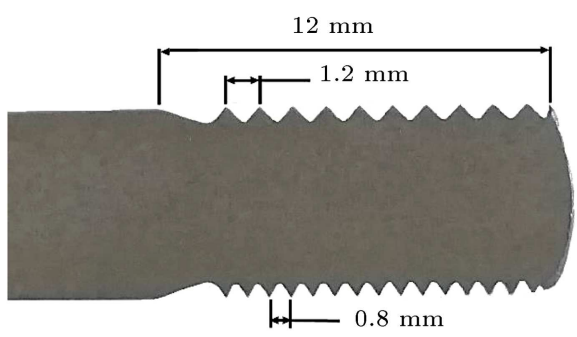

(b)

Figure 2. Two double-edge blades: (a) Up and down sides of the blade have a sharp edge and a toothed edge with $1 \mathrm{~mm}$ pitch, respectively and (b) Up and down sides of the blade have toothed edges with 1.2 and 0.8 mm pitch, respectively. 


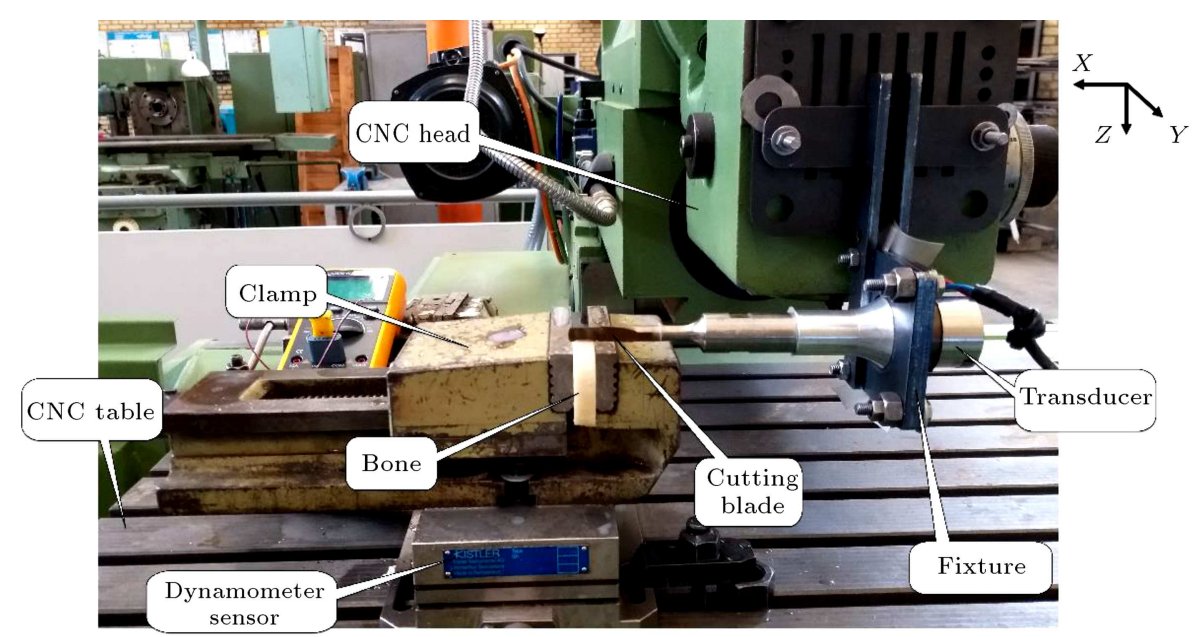

Figure 3. The experimental setup, the tool fixture is clamped to the 3 -axis CNC vertical milling machine, and other parts are labeled on the figure.

moved down in the $X$ and $Z$-directions, respectively. The motion speed in the $X$-direction $(X$-speed) and the $Z$-direction ( $Z$-speed) is essential; thus, each program's feed rate was calculated by considering these two speeds. The $Z$-speed can be considered equivalent to the feed rate during drilling or the tool horizontal velocity in orthogonal or plane cutting. The $X$-speed can be considered as the rotational speed of the tool during drilling.

In the experiments, water was continuously sprayed in the range of $23-25^{\circ} \mathrm{C}$ at room temperature to prevent the cutting temperature from increasing and the bone from drying out. In practice, the incision site must undergo continuous washing and cooling, while as suggested by Kazim et al. [44], it has been shown that this flushing can have an adverse effect on certain neural tissues.

\subsection{Load measurement}

The specimens were fixed between a clamp jaw to allow the measuring of the applied force to the blade during bone cutting. The clamp was mounted on the load cell of the force measurement device. Bone-cutting forces were measured through a Kistler 9252A threecomponent piezoelectric dynamometer (Kistler Instrument AG, Winterthur, Switzerland) and an associated Kistler multichannel charge amplifier type 5019B130 connected to a PC by applying a graphical programming environment (Kistler Dynoware force measurement software) for data visualization and analysis.

\subsection{Design Of Experiment (DOE)}

The DOE is one of the essential parts of an experimental study. Taguchi method or Orthogonal Arrays (OA) and Central Compound Design (CCD) or Response Surface Method (RSM) are the techniques widely applied in reducing the count of the experiments to be assessed the effects of process input parameters on the output responses [45]. Antony [46] has suggested that if identifying the crucial factors and analyzing the interactions therein are required, thoroughly and regularly, the full factorial experiments are the best means to fulfill it.

A full factorial DOE was used to accurately and comprehensively test the existing blades in all possible bone-cutting conditions. According to $[18,19]$ and conditions of the existing equipment and initial tests, the necessary values are determined for the ultrasonic power volume and speeds of the CNC table in the required directions, Table 1.

The calculated feed rates based on the $X$ and $Z$-speeds in the CNC programs are tabulated in Table 2. Because the average thickness of human cortical bone is about $3 \mathrm{~mm}$, the depth of cut in

Table 1. Design parameters and their levels.

\begin{tabular}{|c|c|c|c|c|c|c|}
\hline \multirow{2}{*}{$\begin{array}{c}\text { No. } \\
1\end{array}$} & \multirow{2}{*}{ Tool } & \multicolumn{5}{|c|}{ Level } \\
\hline & & Simple & Sharp & $\begin{array}{c}\text { Toothed edge } \\
(\text { pitch }=0.8 \mathrm{~mm})\end{array}$ & $\begin{array}{c}\text { Toothed edge } \\
(\text { pitch }=1 \mathrm{~mm})\end{array}$ & $\begin{array}{c}\text { Toothed edge } \\
(\text { pitch }=1.2 \mathrm{~mm})\end{array}$ \\
\hline 2 & Ultrasonic power (W) & 0 & & 100 & & 160 \\
\hline 3 & Bone-cutting direction & & $\mathrm{BCW}$ & & $\mathrm{BCL}$ & \\
\hline 4 & $X$-speed $(\mathrm{mm} / \mathrm{min})$ & & 30 & & 50 & \\
\hline 5 & $Z$-speed $(\mathrm{mm} / \mathrm{min})$ & & 5 & & 8 & \\
\hline
\end{tabular}


the whole experiment was considered the same. In cutting thicker bones, the ultrasonic tool's application is limited because the cutting speed slows down. However, even in this case, it can make accurate cuts without rupturing the adjacent tissues $[14,47]$.

Based on the full factorial DOE, 120 experiments including 5 blade shape $\times 3$ ultrasonic power $\times 2$ bone-cutting direction $\times 2 Z$-speed $\times 2 X$-speed were needed, which according to 2 replicates, become 240 .

\section{Results and discussion}

\subsection{The blades cutting behavior}

One of the objectives of this study is to evaluate the different blades' performance in bone cutting. Some of the cut bones are shown in Figure 4. Regardless of the applied loads, the simple blade cannot cut the

Table 2. The calculated feed rate according to $X$ and $Z$-direction speeds.

\begin{tabular}{ccc}
\hline $\begin{array}{c}\boldsymbol{X} \text {-speed } \\
(\mathbf{m m} / \mathbf{m i n})\end{array}$ & $\begin{array}{c}\boldsymbol{Z} \text {-speed } \\
(\mathbf{m m} / \mathbf{m i n})\end{array}$ & $\begin{array}{c}\text { Calculated feed rate } \\
(\mathbf{m m} / \mathbf{m i n})\end{array}$ \\
\hline 30 & 5 & 30.4139 \\
30 & 8 & 50.2494 \\
50 & 5 & 31.0483 \\
50 & 8 & 50.636 \\
\hline
\end{tabular}

bones in all defined cutting states (Figure 4(a)). The sharp blade only scratches the bone surface in the nonultrasonic mode, while the bone samples are cut to a certain extent when ultrasonic power is applied, but the cutting depth is slight, as a result, the cutting forces are low as well (Figure 4(b)). In all experiments, the toothed edge blades cut the bone, while, in the ultrasonic power mode, their performance is faster, the force is smaller, and the blade could reach the end of the defined cutting depth (Figure 4(c)). The size of the teeth affects the cutting force withstanding different cutting conditions, which will be discussed below. If the toothed edge blades do not reciprocate, they will get stuck in the bone and break.

Because only toothed edge blades were able to cut the bone specimens, these samples' surface was analyzed with an optical microscope and surface roughness measurement device (Perthometer M2, Mahr GmbH, Gottingen, Germany). One of the bone surfaces for cutting with or without ultrasonic power by the toothed edge blade (pitch $1 \mathrm{~mm}$ ) is shown in Figure 5 .

In Figure 5(a), the effects of the cutting blade in the form of parallel lines on the surface of the bone are visible. The mean roughness measured in the cutting samples in this state was $R a=3.4 \mu \mathrm{m}$ and $R z=14.2 \mu \mathrm{m}$. After activating the ultrasonic

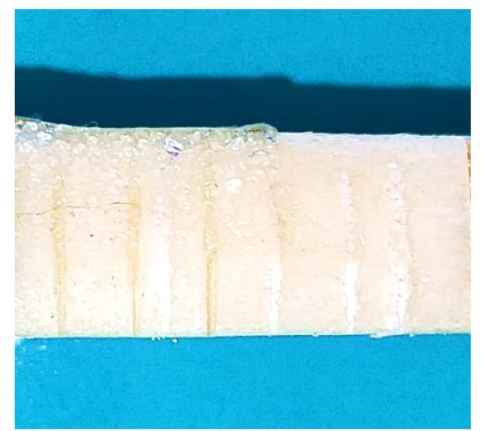

(a)

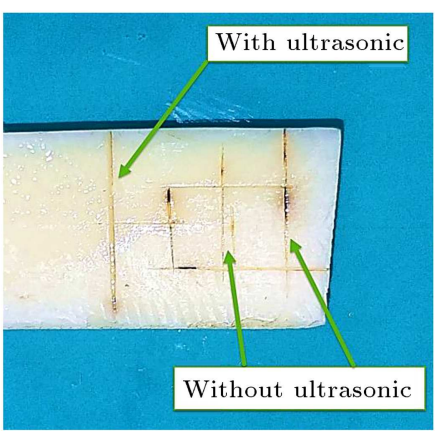

(b)

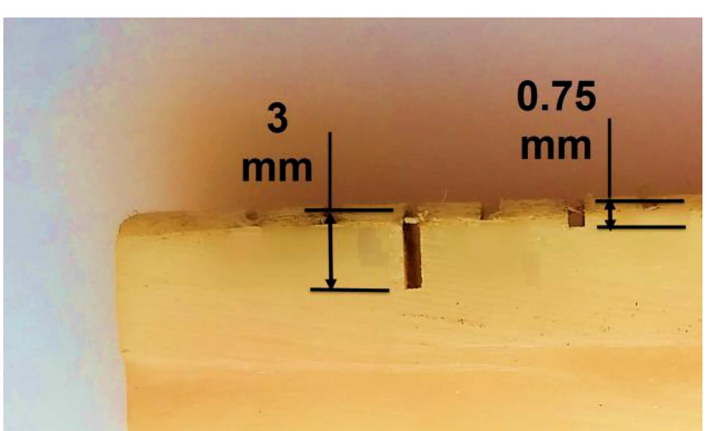

(c)

Figure 4. The effects of different bladescutting performance: (a) Simple blade, (b) sharp blade, and (c) depth of cuts from one of the toothed edge blades with ultrasonic and without ultrasonic mode are 3 and 0.75 mm, respectively.

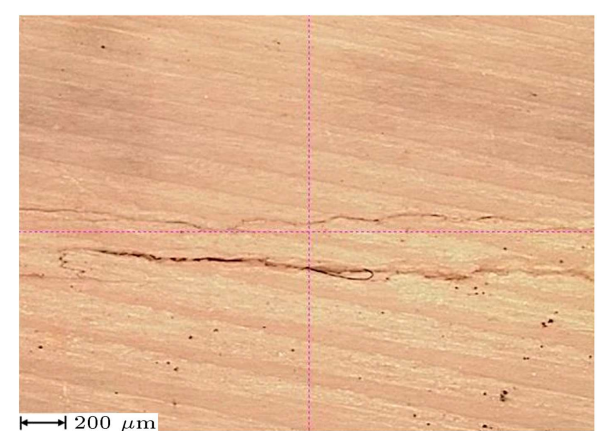

(a)

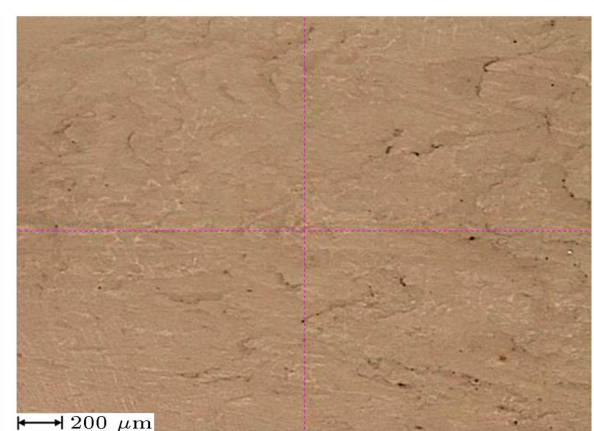

(b)

Figure 5. The surface of cut samples with the toothed edge blade (pitch $1 \mathrm{~mm}$ ): (a) Without ultrasonic and (b) with ultrasonic. 
power (Figure 5(b)), the bone surface shape of the subject, without any specific pattern became irregular; however, the surface roughness average is better than the non-ultrasonic cutting mode $(R a=1.2 \mu \mathrm{m}$ and $R z=8.5 \mu \mathrm{m})$. As reported by Wang et al. [48] and Shu and Sugita [49], the ultrasonic vibrations with reducing the cutting force and the length of fracture cracks improved the shear surface quality.

\subsection{The blades cutting force}

The force-time curves of four different experiments are shown in Figure 6. Almost all tests show similar behavior in terms of the forces distribution shape but vary in forces magnitudes. Muhammad et al. [50] showed that in ultrasonic cutting, applying the vibration to the cutting tool induces intermittent separation of the blade from the bone, leading to a decline in average force levels. Due to the constant depth $(3 \mathrm{~mm})$ of cutting in all experiments and different tool movement speeds, the maximum amount of cutting forces occurs at different times. At the end of each experiment, when the tool was removed from the bone, the forces returned to zero in all directions. As shown in Figure 6, the force exerted on the blades had different distributions in different directions.

As shown in Figure 6, the forces applied to the blades had different distributions in different directions. In all experiments, as the cutting depth increased, the main cutting force exerted on the blade in the $Z$-direction also increased. In some cases, when the direction of movement of the blade in the $X$-direction changed, the force in the $Z$-direction slightly decreased or remained constant. In the $X$-direction, due to the reciprocating motion of the blade, the force amounts changed periodically. In this state, as the cutting depth increased, the forces remained constant or increased, depending on other cutting conditions.

In most experiments, little force was inflicted on the blade in the $Y$-direction because there was no movement. During the cutting process, this force was almost $y$ constant in some cases and slightly increased in other cases; consequently, the inflicted force was not considered in the calculations and analyses.

The Minitab $s / w$ was applied in the statistical analysis to assess the accuracy of experimental data and to identify the significance of the parameters' interactions. The general factorial regression analysis was performed to determine the vital cutting process parameters affecting the inflicted force. The linear and interaction regression coefficients of all factors were considered in this model, and their effects were assessed. In all analyses, the reliability of the hypothetical setting was $95 \%$. The stepwise elimination process with $\alpha=0.15$ was applied to remove insignificant terms and to obtain the best model. In the regression modeling, the blades and bone-cutting directions were considered as the categorical predictors, and ultrasonic power and $X$ - and $Z$-speeds as continuous predictors.

As shown in Figure 4, the forces in the $Y$ direction are of small magnitudes; therefore, they are

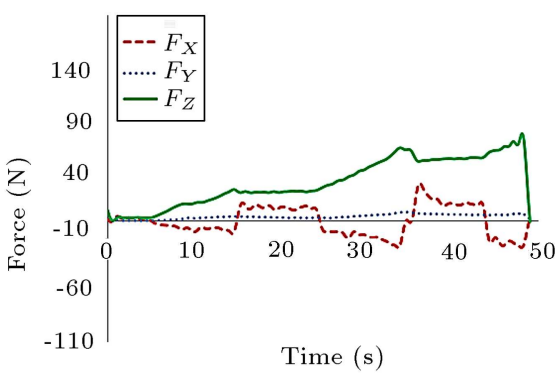

(a)

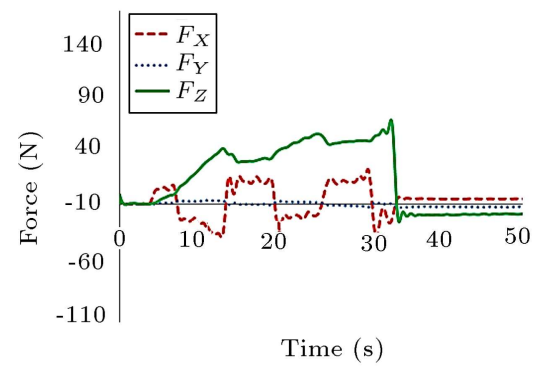

(c)

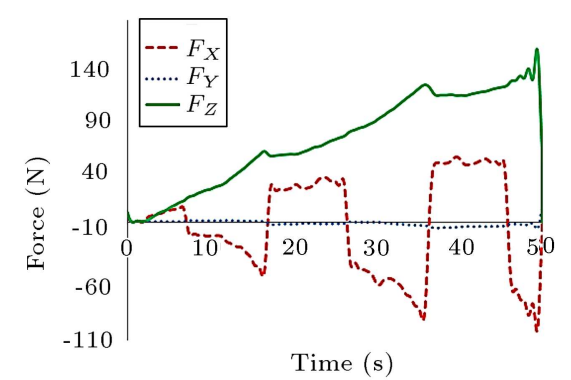

(b)

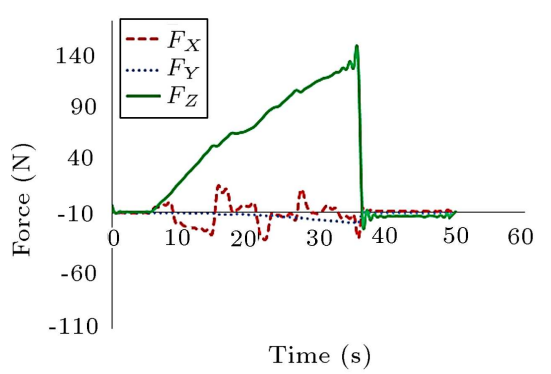

(d)

Figure 6. The force-time curves for four distinct experiments: (a) Toothed edge blade ( $\mathrm{pitch}=1.2 \mathrm{~mm}$ ), $P=100 \mathrm{~W}$, BCL, $X$ and $Z$-speed $=50$ and $5 \mathrm{~mm} / \mathrm{min}$, (b) sharp blade, $P=160 \mathrm{~W}, \mathrm{BCW}, X$ and $Z$-speed $=30$ and $5 \mathrm{~mm} / \mathrm{min},(\mathrm{c})$ toothed edge blade (pitch $=1 \mathrm{~mm}$ ), $P=160 \mathrm{~W}, \mathrm{BCW}, X$ and $Z$-speed $=30$ and $8 \mathrm{~mm} / \mathrm{min}$, and (d) simple blade, $P=100 \mathrm{~W}, \mathrm{BCL}, X$ and $Z$-speed $=50$ and $8 \mathrm{~mm} / \mathrm{min}$. 
not included in the statistical analysis. The effects of input parameters on the $X$ - and $Z$-direction forces are assessed, and the main effect and interaction plots of the final fitted models are presented.

\subsubsection{The main cutting force $\left(F_{Z}\right)$}

The inflicted force on the blade in the $Z$-direction $\left(F_{Z}\right)$ is known as the main cutting force. The maximum value of the main cutting force $\left(F_{Z, \max }\right)$ is considered in the statistical analysis. ANOVA's primary assumptions, including independence of cases, homoscedasticity, and normality of distribution, are
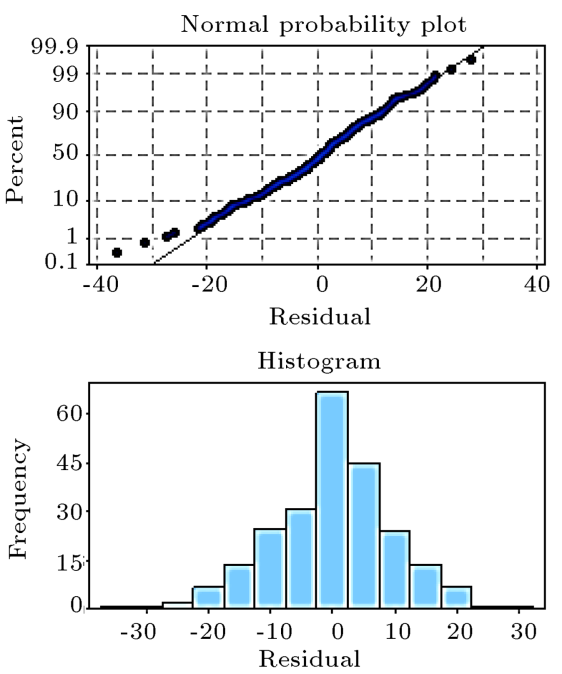

Figure 7. Residual plots for the main cutting force $\left(F_{Z, \max }\right)$.

Table 3. The ANOVA results for $F_{Z, \max }$.

\begin{tabular}{lccccccc}
\hline \multicolumn{1}{c}{ Source } & DF & Seq SS & Adj SS & Adj MS & $\boldsymbol{F}$-value & $\boldsymbol{P}$-value & Contribution \\
\hline Model & 32 & 292011 & 292011 & 9125.4 & 81.31 & 0.000 & $92.63 \%$ \\
Linear & 9 & 234174 & 234174 & 26019.3 & 231.85 & 0.000 & $74.28 \%$ \\
Blade & 4 & 122627 & 122627 & 30656.7 & 273.18 & 0.000 & $38.90 \%$ \\
Bone & 1 & 460 & 460 & 459.9 & 4.10 & 0.044 & $0.15 \%$ \\
Power & 2 & 93767 & 93767 & 46883.5 & 417.77 & 0.000 & $29.74 \%$ \\
$Z$-speed & 1 & 15099 & 15099 & 15098.6 & 134.54 & 0.000 & $4.79 \%$ \\
$X$-speed & 1 & 2222 & 2222 & 2221.7 & 19.80 & 0.000 & $0.70 \%$ \\
2-way interactions & 23 & 57837 & 57837 & 2514.7 & 22.41 & 0.000 & $18.35 \%$ \\
Blade*bone & 4 & 3572 & 3572 & 893.1 & 7.96 & 0.000 & $1.13 \%$ \\
Blade*power & 8 & 42732 & 42732 & 5341.5 & 47.60 & 0.000 & $13.56 \%$ \\
Blade* $Z$-speed & 4 & 1330 & 1330 & 332.5 & 2.96 & 0.021 & $0.42 \%$ \\
Blade* $X$-speed & 4 & 2128 & 2128 & 532.1 & 4.74 & 0.001 & $0.68 \%$ \\
Bone* $Z$-speed & 1 & 445 & 445 & 445.5 & 3.97 & 0.048 & $0.14 \%$ \\
Power* $Z$-speed & 2 & 7629 & 7629 & 3814.6 & 33.99 & 0.000 & $2.42 \%$ \\
Error & 207 & 23230 & 23230 & 112.2 & & & $7.37 \%$ \\
Lack-of-fit & 87 & 18713 & 18713 & 215.1 & 5.71 & 0.000 & $5.94 \%$ \\
Pure error & 120 & 4517 & 4517 & 37.6 & & & $1.43 \%$ \\
Total & 239 & 315242 & & & & & $100.00 \%$ \\
\hline & & & & & & & \\
\hline
\end{tabular}

assessed to examine the goodness-of-fit herein. The residual plots of the main cutting force $\left(F_{Z \text {,max }}\right)$ are shown in Figure 7.

As can be seen, the residual plot versus the observation order does not show any pattern, indicating that the data are independent. Furthermore, residuals are randomly scattered around zero, confirming that the data had the same variance. The normal probability plot and histogram of residuals confirm the normality assumption.

The ANOVA results for $F_{Z \text {, max }}$ are tabulated in Table 3, where only the factors where the $P$-value
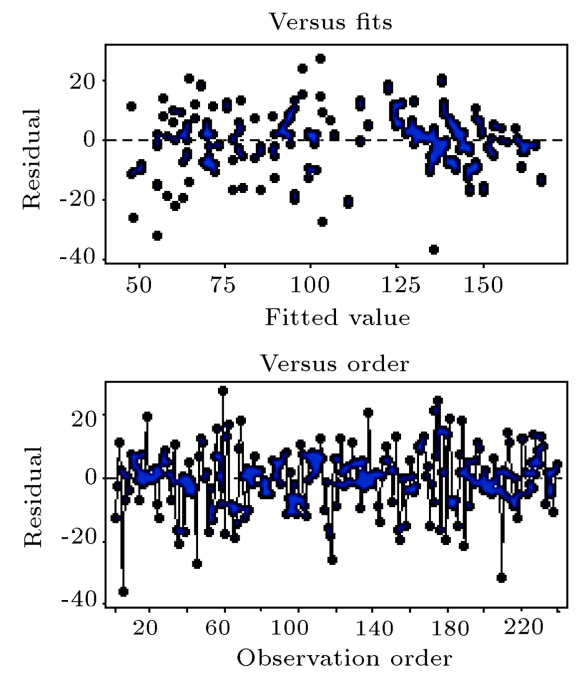
is less than 0.05 are of concern. A small $P$-value indicates the high importance of relevant variables or interactions [42].

According to the ANOVA table, the linear factor contributing $74.28 \%$ in the final model had a greater effect than the higher degree factor $(18.35 \%)$. The blade, power, and $Z$-speed with $38.90 \%, 29.74 \%$, and $4.79 \%$ contribution, respectively, had the highest effect on $F_{Z \text {,max }}$. In the provided statistical model, the interaction between the variables was contributing. In this sense, the interaction between power and blade was $13.56 \%$ and the interaction between power and $Z$-speed was 2.42 , respectively, which had the greatest impact on $F_{Z}$ and max. In the $F_{Z \text {,max }}$ statistical analysis, the adjusted $R$-squared value $\left(R_{\text {adj }}^{2}\right)$ is $91.49 \%$. The regression equations for $F_{Z \text {,max }}$ are presented in Table 4 .

The effect of different cutting factors on $F_{Z \text {,max }}$ is shown in Figure 8.

As shown in Figure 8, in all experiments, the simple blade had the highest $F_{Z \text {,max }}(149.8 \mathrm{~N})$, because it exerted pressure on the bone surface instead of cutting and penetrating the bone. The toothed edge blade with a tooth pitch of $1.0 \mathrm{~mm}$ had the lowest
$F_{Z \text {,max }}(91.5 \mathrm{~N})$. These results showed that teething the cutting edge not only improved the cutting process but also reduced the cutting force by about $40 \%$. The bonecutting direction change in parallel or perpendicular to the bone's longitudinal axis, shows little effect on the $F_{Z \text {, max }}$ (about $2.5 \%$ ), while the BCL samples have more $F_{Z \text {, max }}$. According to the results of Alam [40], in the BCL mode, the osteon's direction and the tool movement are similar, which makes osteons more compressed rather than being cut.

Applying the ultrasonic power and increasing its magnitude significantly reduced the main cutting force to a point where the $F_{Z \text {,max }}$ decreased by about $27.2 \%$. This effect of ultrasonic power is consistent with the results illustrated in $[14,30,40]$. Low contact of the tool with the cutting area, the formation of broken chips, and reduced friction are some of the reasons for this effect. Increasing the vibration amplitude and frequency directly increases the effect on the ultrasonic power, which will cause the main cutting force to decrease [8,51]. However, a frequency of less than $20 \mathrm{kHz}$ generates annoying and audible noise, and high amplitude can lead to a threat to nerves and soft

Table 4. Regression equations for $F_{Z \text {,max }}$.

\begin{tabular}{lcc}
\hline \multicolumn{1}{c}{ Blade } & Bone & $\boldsymbol{F}_{\boldsymbol{Z} \text {,max }}$ \\
\hline Simple & & $140.7(127.9)-0.223$ power $-1.18(0.63) Z$-speed $+0.287 X$-speed +0.0447 power* $Z$-speed \\
Sharp & & $167.3(166.2)-0.581$ power $+0.08(1.90) Z$-speed $-0.504 X$-speed +0.0446 power* $Z$-speed \\
Toothed-0.8 mm & BCL & $126.7(108.5)-0.642$ power $+3.49(5.30) Z$-speed $-0.389 X$-speed +0.0446 power* $Z$-speed \\
Toothed-1 mm & & $150.5(134.1)-0.736$ power $-0.04(1.78) Z$-speed $-0.446 X$-speed +0.0447 power* $Z$-speed \\
Toothed-1.2 mm & & $155.5(131.2)-0.724$ Power $+0.19(2.00) Z$-speed $-0.469 X$-speed +0.0447 power* $Z$-speed \\
\hline
\end{tabular}

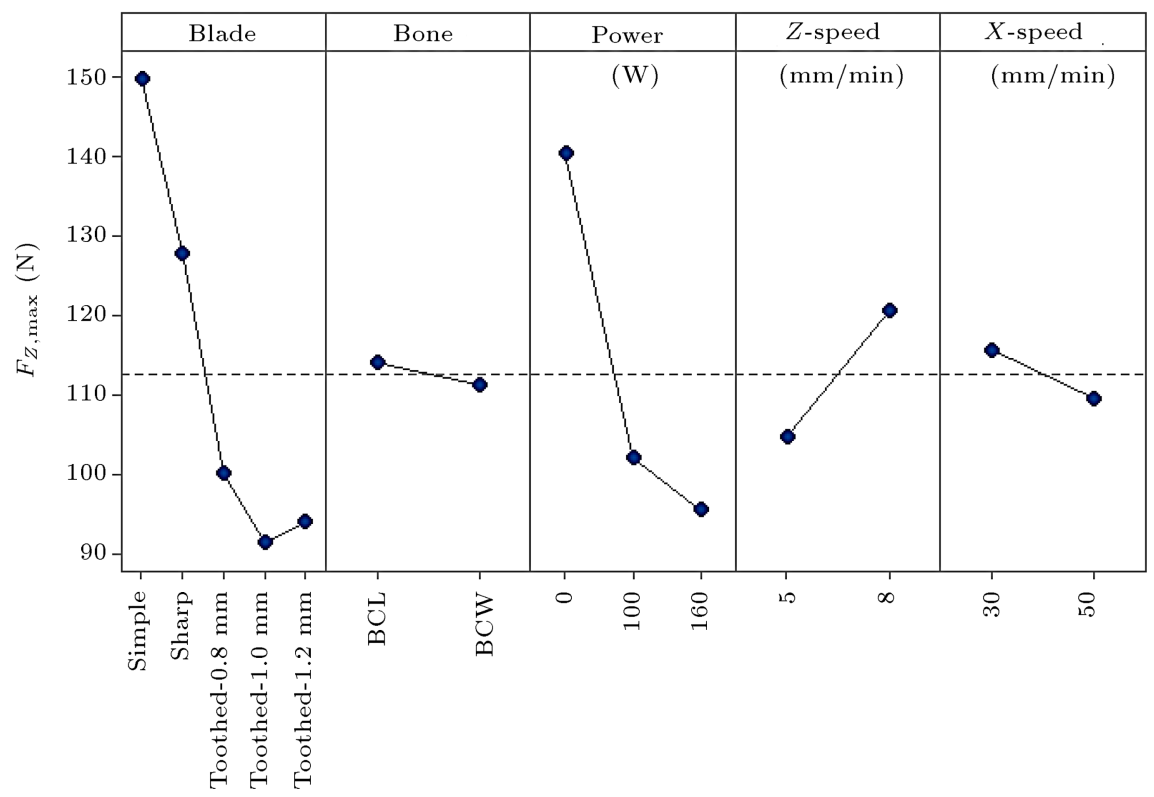

Figure 8. The main effect plots of $F_{Z \text {,max }}$. 
tissues. Ying et al. [30] proposed a frequency in the range of $20-30 \mathrm{kHz}$ with a vibration amplitude of $15-$ 25 microns.

Increasing the ultrasonic power from 100 to $160 \mathrm{~W}$ has a less decreasing effect on the main cutting force that is only about $6.8 \%$ reduction in the $F_{Z \text {, max }}$. The longer the contact time between the tool and bone, the higher the cutting force [30]. In the nonultrasonic state, the blade-bone contact is continuous. On the contrary, under the action of ultrasonic power, this contact becomes intermittent [8]; consequently, applying ultrasonic waves to reduce the cutting force is more effective than increasing the amount of ultrasonic power.

Changes in the $Z$ - and $X$-speed have different effects on the $F_{Z \text {,max }}[20,52,53]$. An increase in $Z$-speed will increase the maximum cutting force by $15.1 \%$, while an increase in $X$ - speed will reduce this force by $5.3 \%$. It could be deduced that the effect of tool penetration speed on the main cutting force is more significant than its reciprocating speed. These results can be attributed to an increase in the strain rate, the longer contact time between the cutting edge of the tool and the bone [30], and the increase in friction between them [22].

The interaction plots of $F_{Z \text {,max }}$ are shown in Figure 9.

According to the plots in Figure 9, the following results can be summarized: The simple blade could not cut the bone in any defined pattern; therefore, in this case, changing the cutting direction from BCL to $\mathrm{BCW}$ will not affect the cutting force. As for the other parameters, increasing the volume of this parameter will increase the main cutting force, because it will generate more pressure on the tool. In the continuation of this section, the simple blade is removed from the assessments.

While the toothed edge blades have little dependency on the variation of cutting direction, the sharp blade shows more sensitivity to the change of direction. The sharp blade is different from the toothed blade and has a larger $F_{Z \text {,max }}$ in $\mathrm{BCW}$ cutting than the BCL mode. Similar to the results of Sui et al. [42], the reason for this sharp blade behavior can be associated with more friction and entrapment inside the bone and osteons. Especially in the BCW mode, where the osteons are perpendicular to the path of the blade movement, the sharp blade cannot cut them. The toothed edge blades have a saw-like behavior when cutting, and their friction will be smaller than that of a sharp blade. This effect causes the toothed edge blades to have less main cutting force than other blades in all cutting modes. For this reason, in the $\mathrm{BCW}$ cutting mode either, there is less $F_{Z}$ than in the BCL mode. Meanwhile, the toothed edge blade with a tooth pitch of $1 \mathrm{~mm}$ has the least sensitivity to changes in the cutting direction.

The effect of applying ultrasonic power in decreasing the $F_{Z \text {,max }}$ in the toothed edge blades, is much higher than that of the sharp tool $(40.9 \%$ versus $14.1 \%$ ). In comparison, increasing the ultrasonic power from $100 \mathrm{~W}$ to $160 \mathrm{~W}$ can reduce the main cutting force of sharp tools, and the effect is more significant (about 20.1\%). Zhang et al. [14] showed that in sharp tools, the friction and contact surface between the bonecutting site and the edge of the blade is larger than that
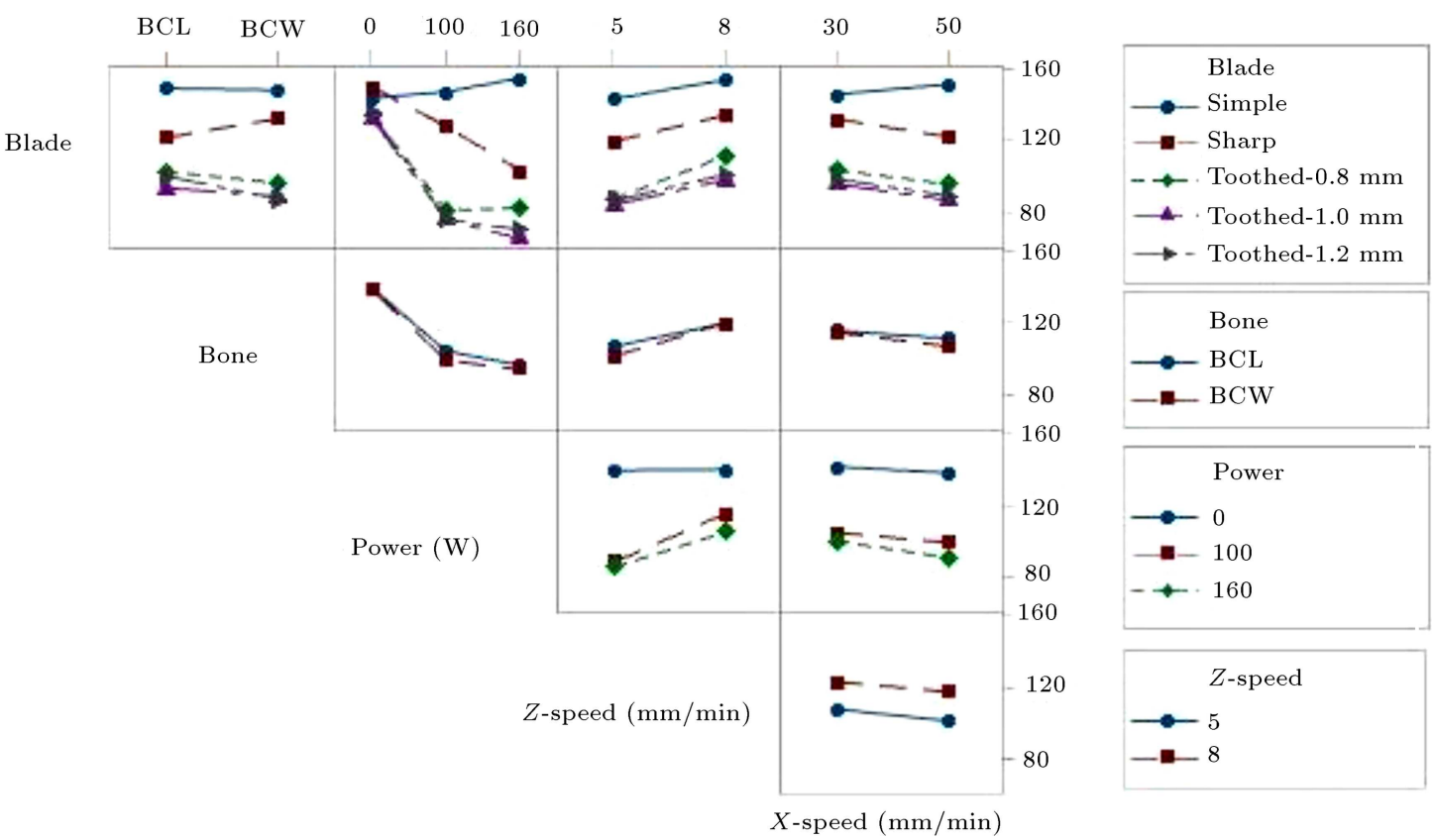

Figure 9. The interaction plots of $F_{Z \text {,max }}$. 
of a toothed edge blade. As a result, applying the ultrasonic power and increasing its value, the sharp blade's cutting force decreases almost in a linear manner.

The toothed edge blades show a different reaction to the increase in ultrasonic power. The main cutting force in the blade with a pitch of $0.8 \mathrm{~mm}$ hardly changed, but the main cutting force in the blades with a pitch of 1.2 and $1 \mathrm{~mm}$ was reduced by about $5.9 \%$ and $13.7 \%$, respectively. As reported by Wang et al. [48], it can be said that the ultrasound power generates microvibration at the edge of the blade, causing micro-cracks to appear at the bone-cutting site and reducing its strength, which ultimately leads to the reduction of the cutting force.

Compared with BCL mode, BCW cut is more sensitive to changing parameters. For example, applying ultrasonic power in the BCW mode and increasing the $Z$-speed would decrease and increase the $F_{Z \text {,max }}$ of this mode by about $5 \%$ more than that of the BCL mode, respectively. This state can be related to the osteons' direction and their resistance to cutting; the ultrasonic power could be reducing this dependence [54].

In the case of cutting without the ultrasonic power, changes in the tool speeds are almost ineffective. When reducing the main cutting force with higher $Z$ - and $X$-speeds, the effect of increasing the ultrasonic power is greater. Since the increase of the tool speed will increase the friction between the blade and the cutting site, the ultrasonic power can reduce this friction [54,55], which in turn could lead to the reduction of $F_{Z \text {,max }}$.

\subsubsection{The cutting resistance force $\left(R F_{X}\right)$}

The force inflicted on the cutting blade along its longitudinal displacement direction $\left(R F_{X}\right)$ is another key factor affecting cutting efficiency. Khambay and Walmsley [56] named this force the longitudinal force for the first time and studied the parameters that affect this force. The sign of the measured $R F_{X}$ changes due to the reciprocating motion of the blade in the $X$-direction. The $R F_{X}$ values become more or less (or positive and negative) in each cycle motion of the tool due to the sinusoidal nature of the ultrasonic vibrations. The negative values (or the $R F_{X}$ decreasing) indicate that the tool is moved away from the cutting site and exerts a pushing force to the backward direction, which causes blade slippage on the bone and transfers the pressure to the operator's hand [57]. As described by Zhang et al. [14], in practice, surgeons exert more pressure on the ultrasonic handpiece to overcome this force, which reduces the efficiency of the instrument and can even damage some surrounding tissues. Consequently, some experts recommend that the cutting blade edge be kept perfectly perpendicular to the bone surface and the pressure exerted on the tool be lower than 400 gram-force as much as possible $[58,59]$. It is essential to concentrate on this resistance force and explain the influential factors therein. The residual plots of cutting resistance force ( RFx) confirm the assumptions of independence, equal variance, and normal distribution of the data, as shown in Figure 10.

In the statistical analysis, the maximum absolute volume of the cutting resistance of the blade $\left(\left|R F_{X, \max }\right|\right)$ was considered. The ANOVA results for $\left|R F_{X, \max }\right|$ are tabulated in Table 5 .

It can be seen from the table that the effect of the linear factor on the resistance accounts for $71.45 \%$ of the result, which is higher than the effect of the 2-way interaction on the resistance (22.21\%). The
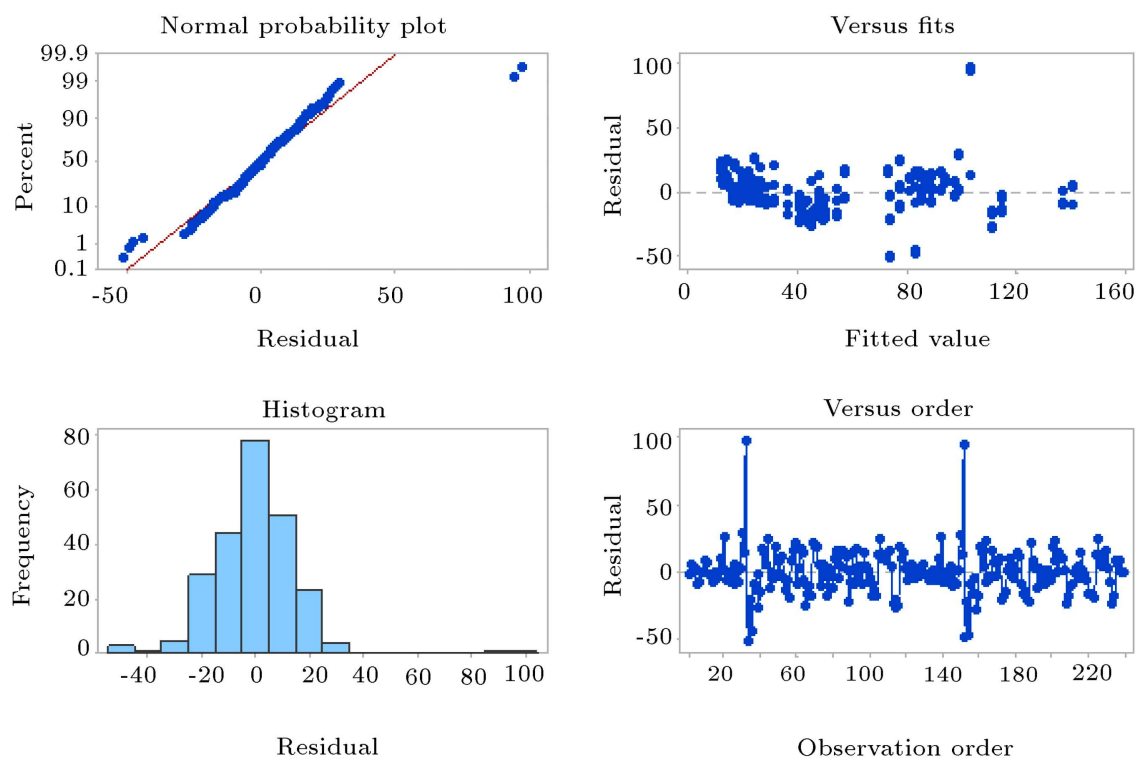

Figure 10. Residual plots for the cutting resistance force $\left(R F_{X}\right)$. 
Table 5. ANOVA results for $\left|R F_{X, \max }\right|$.

\begin{tabular}{lccccccc}
\hline \multicolumn{1}{c}{ Source } & DF & Seq SS & Adj SS & Adj MS & $\boldsymbol{F}$-value & $\boldsymbol{P}$-value & Contribution \\
\hline Model & 29 & 313822 & 313822 & 10821.4 & 85.86 & 0.000 & $92.22 \%$ \\
Linear & 9 & 243144 & 243144 & 27016.0 & 214.36 & 0.000 & $71.45 \%$ \\
Blade & 4 & 129141 & 129141 & 32285.3 & 256.17 & 0.000 & $37.95 \%$ \\
Bone & 1 & 1427 & 1427 & 1426.6 & 11.32 & 0.001 & $0.42 \%$ \\
Power & 2 & 111339 & 111339 & 55669.4 & 441.71 & 0.000 & $32.72 \%$ \\
$Z$-speed & 1 & 649 & 649 & 649.2 & 5.15 & 0.024 & $0.19 \%$ \\
$X$-speed & 1 & 589 & 589 & 588.6 & 4.67 & 0.032 & $0.17 \%$ \\
2-way interactions & 20 & 70677 & 70677 & 3533.9 & 28.04 & 0.000 & $20.77 \%$ \\
Blade*Bone & 4 & 7649 & 7649 & 1912.2 & 15.17 & 0.000 & $2.25 \%$ \\
Blade*Power & 8 & 54889 & 54889 & 6861.2 & 54.44 & 0.000 & $16.13 \%$ \\
Blade* $X$-speed & 4 & 3772 & 3772 & 942.9 & 7.48 & 0.000 & $1.11 \%$ \\
Power* $Z$-speed & 2 & 3294 & 3294 & 1647.0 & 13.07 & 0.000 & $0.97 \%$ \\
Power* $X$-speed & 2 & 1073 & 1073 & 536.7 & 4.26 & 0.015 & $0.32 \%$ \\
Error & 210 & 26467 & 26467 & 126.0 & & & $7.78 \%$ \\
Lack-of-fit & 90 & 23627 & 23627 & 262.5 & 11.09 & 0.000 & $6.94 \%$ \\
Pure error & 120 & 2840 & 2840 & 23.7 & & & $0.83 \%$ \\
Total & 239 & 340288 & & & & & $100.00 \%$ \\
\hline
\end{tabular}

Table 6. Regression equations for $\left|R F_{X, \max }\right|$.

\begin{tabular}{lll}
\hline \multicolumn{1}{c}{ Blade } & Bone & \multicolumn{1}{c}{$\left|\boldsymbol{R} \boldsymbol{F}_{\boldsymbol{X} \text {, } \text { max }}\right|$} \\
\hline Simple & & $29.71(31.24)-0.1882$ power $-1.20 Z$-speed +0.0265 power* $Z$-speed \\
Sharp & & $147.14(121.13)-0.5525$ power $-1.20 Z$-speed +0.0265 power* $Z$-speed \\
Tooted-0.8 mm & BCL $(B C W)$ & $103.53(98.55)-0.6047$ power $-1.20 Z$-speed +0.0265 power* $Z$-speed \\
Toothed-1 mm & $83.57(90.56)-0.5414$ power $-1.20 Z$-speed +0.0265 power* $Z$-speed \\
Toothed-1.2 mm & $95.01(93.10)-0.5997$ power $-1.20 Z$-speed +0.0265 power* $Z$-speed \\
\hline
\end{tabular}

analysis of ANOVA data showed that changing the geometry of the blade and the input power had the greatest impact on $\left|R F_{X, \max }\right|$. The blade, power, and their interaction by $37.95 \%, 32.72 \%$, and $16.13 \%$ contribution, respectively, were the parameters that had the greatest impact on $\left|R F_{X, \max }\right|$. The $R_{\text {adj }}^{2}$ of the statistical fitted model was $91.15 \%$ for $\left|R F_{X, \max }\right|$. The regression equations propose for $\left|R F_{X \text {,max }}\right|$ based on the blade geometry and bone-cutting directions are expressed in Table 6 .

The main effect plots of $\left|R F_{X, \max }\right|$ are shown in Figure 11.

As shown in Figure 11, the behavior of the cutting resistance force was different from the behavior of the main cutting force in some defined variables. The simple blade not only does not penetrate the bone in any defined cutting situation but also slips on the bone surface and scratches it, the result of which reveals as the least resistant cutting force.

An increase in the sharp blade's cutting depth results in more tool penetration inside the bone and prevents slippage; thus, the sharp blade has the highest $\left|R F_{X, \max }\right|(93.5 \mathrm{~N})$. The toothed edge blades have lower $\left|R F_{X, \max }\right|$ than the sharp blade, once more, revealing that the toothed edge blade with $1 \mathrm{~mm}$ pitch has a better position with lower $\left|R F_{X, \max }\right|(47.6 \mathrm{~N})$. Pan [60] points out that having the tooth on the cutting edge reduces the friction coefficient between the blade and bone, which, consequently, reduces the cutting resistance force.

The effect of the change of cutting direction on the cutting resistance force was greater than that of the main cutting force ( $10 \%$ versus $2.5 \%$ ), while the change of the velocities defined for the tool had a smaller effect on the $\left|R F_{X, \max }\right|$. In general, in agreement with Yeager et al. [41] and Sui et al. [42], increasing the $Z$ - and $X$ speed of the tool and changing the cutting direction from BCW to BCL will increase the $\left|R F_{X \text {, max }}\right|$ on the blades. The cutting resistance force is high in the BCL specimens because the cracks that are usually between the osteons and along the cement line begin to grow in them and propagate [42]. 


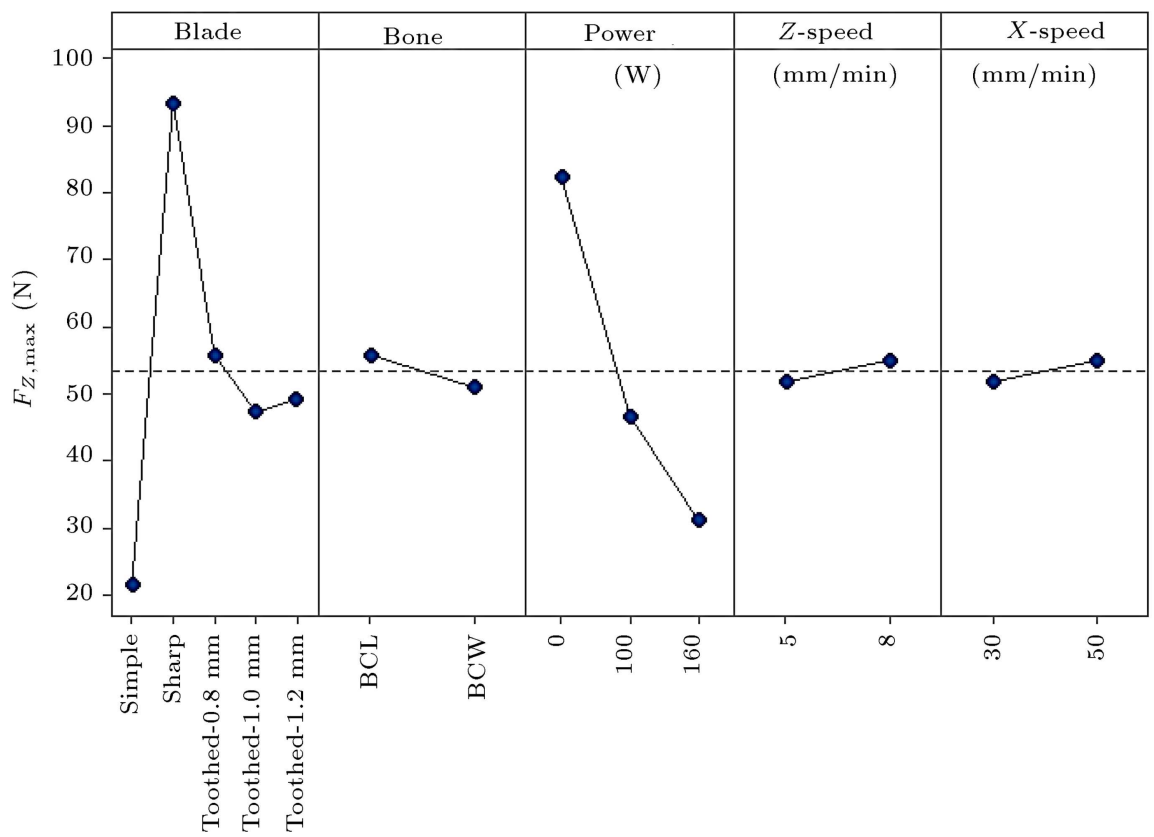

Figure 11. The main effect plots of $\left|R F_{X, \max }\right|$.

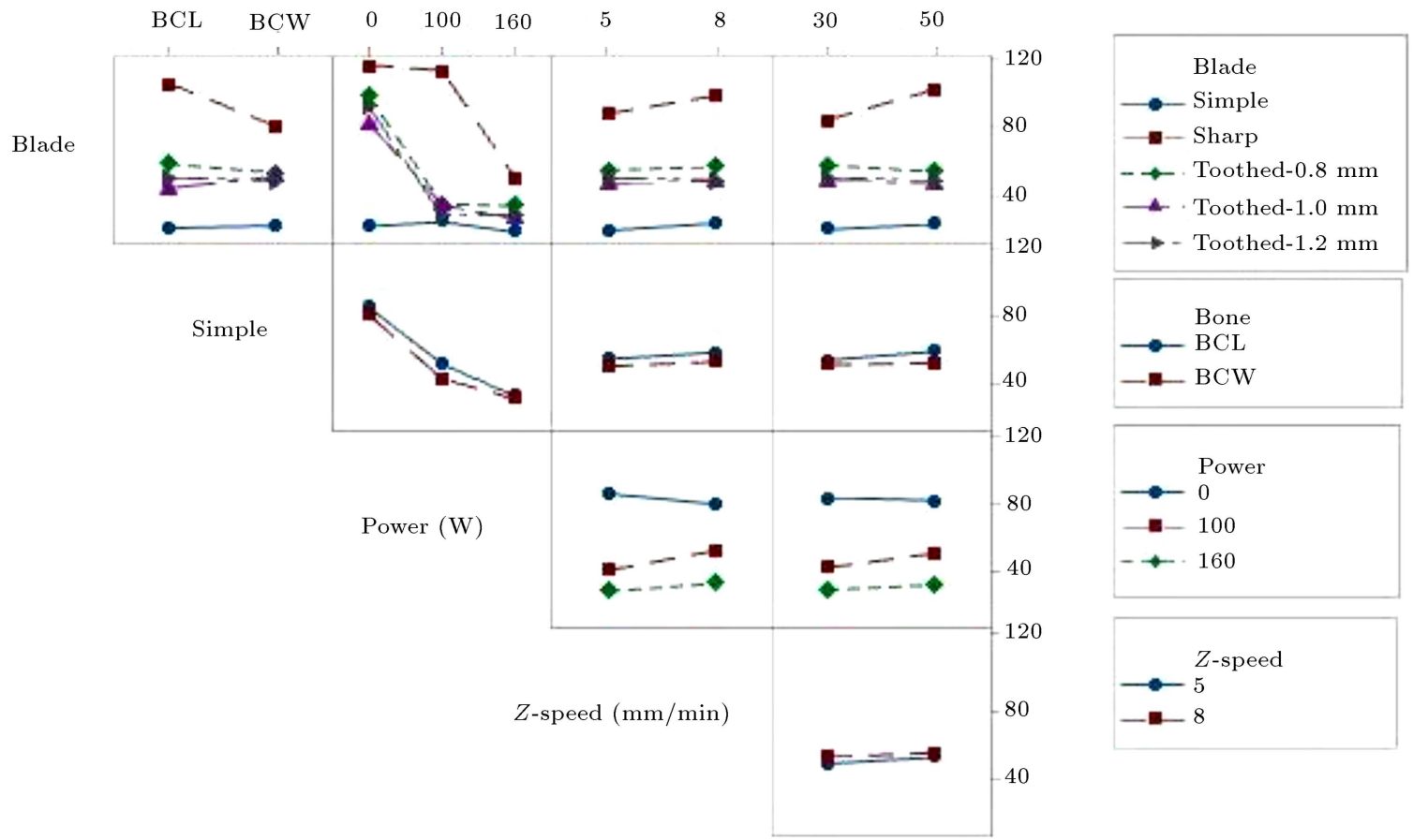

$X$-speed $(\mathrm{mm} / \mathrm{min})$

Figure 12. The interaction plots of the $\left|R F_{X, \max }\right|$.

The ultrasonic power has a high contribution and, like the main cutting force, reduces the cutting resistance force. The important note here is that an increase in the ultrasonic power amount (100 to $160 \mathrm{~W}$ ) has a more significant effect in reducing the $\left|R F_{X \text {, max }}\right|$ than the $F_{Z, \max }(33.4 \%$ compared to $6.4 \%)$. Due to the application of ultrasonic power and the increase of its volume, the blade slippages at the cutting site and reduces the contact with the bone surface [61], which is the cause of this reduction effect.

The interaction plots of $\left|R F_{X, \max }\right|$ are shown in Figure 12. According to Figure 12, the following results are expressed. In all experiments run with the simple blade, and with all changes made in the input param- 
eters, due to not being able to cut bone, this tool's cutting resistance force does not change significantly and is almost constant. Therefore, the simple blade is not included in the following evaluations.

Among all the tools, the change in cutting direction from BCL to $\mathrm{BCW}$ shows the greatest effect in reducing the $\left|R F_{X, \max }\right|$ in the sharp blade by $27.4 \%$. The reason can be related to this blade's low cutting ability and its more slippage on the bone surface in the $\mathrm{BCW}$ direction. The toothed edge blades are less sensitive to the change in cutting direction, and the $\left|R F_{X, \max }\right|$ is almost constant. The toothed edge blade with a $1 \mathrm{~mm}$ pitch has a slight increase in $\left|R F_{X \text {,max }}\right|$, which can be ignored.

Applying the ultrasonic power to the toothed edge blades results in a considerable reduction in $\left|R F_{X, \max }\right|$ $(73.7 \%)$. In contrast, an increase in the ultrasonic power magnitude from 100 to $160 \mathrm{~W}$ did not affect the $\left|R F_{X, \max }\right|$. This parameter has a different effect on the sharp blade so that cutting with ultrasonic power up to $100 \mathrm{~W}$ does not have much effect on the $\left|R F_{X, \max }\right|$; however, by increasing its volume to $160 \mathrm{~W}$, the $\left|R F_{X, \max }\right|$ is significantly reduced $(62.7 \%)$. The application of ultrasound and its micro-impact effect will reduce the surface contact between the tool and the bone, and reduce the contact time between each tooth and the bone [8]. In this case, the possibility of the tool edge getting stuck in the bone is reduced; therefore, the resistance is reduced. The contact and friction surface of the sharp blade with the bone is high, so to decrease the $\left|R F_{X, \max }\right|$, the ultrasonic power must be applied, and the amount of this power must increase (more than $100 \mathrm{~W}$ ).

The $\left|R F_{X, \max }\right|$ in the toothed edge blades does not show any sensitivity to the changes of cutting speeds, but an increase in the $Z$ - and $X$-speeds accompany by the rise in the $\left|R F_{X \text {, max }}\right|$ of the sharp blade. An increase in $Z$ - and $X$-speeds led to an increase in contact time between the sharp blade and bone in each cycle, resulting in an increase in cutting resistance force of approximately $28 \%$. Similar to the results of Muhammad [62], at higher speeds of the tool, the volume of the material removed by the tool increases which leads to the exerted of more forces to the blade.

The effect of applying ultrasonic power to reduce the $\left|R F_{X, \max }\right|$ in the BCW cuts was slightly higher than that of the BCL cuts, but by increasing the ultrasonic power magnitude in the BCL cuts, the $\left|R F_{X \text {, max }}\right|$ decrease. Changes in the bone-cutting direction and the tool speeds do not depend on each other in terms of the effect on the cutting resistance force [42].

At high $\left|R F_{X, \max }\right|$ volumes (like in non-ultrasonic cuttings) and its minimum magnitudes (like in highpower ultrasonic cuttings with $160 \mathrm{~W})$, changes in the blade speeds do not have much influence on the $\left|R F_{X, \max }\right|$. Even in the non-ultrasonic mode, by increasing the $Z$-speed of the tool, the $\left|R F_{X \text {, max }}\right|$ decreases. Because in these states, the ultrasonic power and its magnitudes have a prominent role in the resistance force, the other factor's effect is negligible. In the low-power ultrasonic cuts $(100 \mathrm{~W})$, the cutting resistance force is more affected by changes in the tool speeds.

\section{Conclusion}

The effect of different parameters on the cutting force of the cortical bone is comprehensively assessed. The input parameters include the blades with different geometries ( 5 states), presence and absence of ultrasound power with different magnitudes (3 states), types of cutting bone directions ( 2 states), and change in the horizontal (2 states) and vertical (2 states) speed of the cutting tool. For the vertical cutting force (force in the $Z$-direction) and its longitudinal movement (force in the $X$-direction), the force acting on the blade is considered more critical. The obtained results are summarized as follows:

- The contribution of the individual parameters to the cutting forces is more than that of their interactions. The blade geometry and the input power with $82.2 \%$ and $86.6 \%$ contribution in $F_{Z, \max }$, and $\left|R F_{X, \max }\right|$ respectively, are the most effective factors in the force inflicted on the cutting tool;

- Compared with sharp and simple blades, toothed edge blades have faster speed and better cutting ability, and the cutting force is smaller. Increasing the pitch of the toothed edge blade to $1 \mathrm{~mm}$ will reduce the cutting force, but a pitch greater than $1 \mathrm{~mm}$ will produce more cutting force;

- Perpendicular cuts on the cortical bone axis need fewer cutting forces than parallel cuts;

- Increasing the $Z$-speed increases both $F_{Z \text {,max }}$, and $\left|R F_{X \text {,max }}\right|$, while increasing the $X$-speed increases the $\left|R F_{X \text {, max }}\right|$ and decreases the $F_{Z \text {,max }}$;

- In general, the equipment parameters (blade geometry and power system) are more effective in $F_{Z \text {,max }}$, and $\left|R F_{X, \max }\right|$ than process parameters (blade speed in the $X$ and $Z$-directions);

- Non-ultrasonic cutting, together with inappropriate geometry of the cutting tool edge, leads to cutting inefficiency;

- In general, applying ultrasonic power and increasing its magnitude reduces the forces exerted on the cutting blade;

- Applying the blade with a toothed edge and applying ultrasonic power more than $100 \mathrm{~W}$ at low $Z$ speed and high $X$-speed is recommended to perform bone-cutting with high efficiency and low cutting forces; 
- If the $Z$-speed is to be increased, it is better to increase the ultrasonic power and the $X$-speed to reduce the total cutting force;

- If you want to use it in a sharp ultrasound blade (similar to a knife) to cut the cortical bone, it is best to apply the ultrasound with high-power and in the cuts parallel to the bone axis.

\section{Acknowledgment}

This work was supported by the Isfahan University of Technology. The authors would like to thank for IUT manufacturing workshop personnel for providing and performing the bone-cutting tests.

\section{Nomenclature}

$\begin{array}{ll}\text { ANOVA } & \text { Analysis of variance } \\ \text { CCD } & \text { Central Compound Design } \\ \text { DOE } & \text { Design Of Experiments } \\ \text { RSM } & \text { Response Surface Method } \\ \text { OA } & \text { Orthogonal Arrays } \\ F & \text { Force }(\mathrm{N}) \\ f & \text { Frequency }(\mathrm{Hz}) \\ A & \text { Amplitude }(\mathrm{m}) \\ x & \text { Displacement }(\mathrm{m}) \\ a & \text { Acceleration }\left(\mathrm{m} / \mathrm{s}^{2}\right) \\ m & \text { Mass }(\mathrm{kg}) \\ t_{0} & \text { Initial time }(\mathrm{s}) \\ t & \text { Time }(\mathrm{s})\end{array}$

\section{References}

1. Takabi, B. and Tai, B.L. "A review of cutting mechanics and modeling techniques for biological materials", Medical Engineering \& Physics, 45, pp. 1-14 (2017).

2. Wallace, R.J. "A comparison of past, present and future bone surgery tools", International Journal of Orthopaedics, 2(3), pp. 266-269 (2015).

3. Wu, W., Yao, G., Zhang, D., et al. "Study on the low-power tissue cutting of electrosurgery assisted with Heat", Procedia CIRP, 89, pp. 228-232 (2020).

4. Liao, Z., Axinte, D.A., and Gao, D. "A novel cutting tool design to avoid surface damage in bone machining", International Journal of Machine Tools and Manufacture, 116, pp. 52-59 (2017).

5. Gordon, A., Looi, T., Drake, J., et al. "An ultrasonic bone cutting tool for the da Vinci research kit", 2018 IEEE International Conference on Robotics and Automation (ICRA), pp. 6645-6650 (2018).

6. Pan, Z., Lucas, M., and Ganilova, O. "Study of an ultrasonic bone cutting blade for orthopaedic surgery", 2012 IEEE International Ultrasonics Symposium, pp. $1-4$ (2012).
7. Robiony, M., Franz, L., Costa, F., et al. "Piezosurgery: A true revolution for nasal bone osteotomies in rhinoplasty", Plastic and Reconstructive Surgery Global Open, 4(6), pp. 1-2 (2016).

8. Alam, K., Khan, M., and Silberschmidt, V.V. "Analysis of forces in conventional and ultrasonically assisted plane cutting of cortical bone", Proceedings of the Institution of Mechanical Engineers, Part H: Journal of Engineering in Medicine, 227(6), pp. 636-642 (2013).

9. Schaeren, S., Jaquiéry, C., Heberer, M., et al. "Assessment of nerve damage using a novel ultrasonic device for bone cutting", Journal of Oral and Maxillofacial Surgery, 66(3), pp. 593-596 (2008).

10. Harder, S., Wolfart, S., Mehl, C., et al. "Performance of ultrasonic devices for bone surgery and associated intraosseous temperature development", International Journal of Oral \& Maxillofacial Implants, 24(3), pp. 484-490 (2009).

11. Pereira, C.C.S., Gealh, W.C., Meorin-Nogueira, L., et al. "Piezosurgery applied to implant dentistry: clinical and biological aspects", Journal of Oral Implantology, 40(S1), pp. 401-408 (2014).

12. Yao, G., Zhang, D., Geng, D., et al. "Improving anti-adhesion performance of electrosurgical electrode assisted with ultrasonic vibration", Ultrasonics, $\mathbf{8 4}$, pp. 126-133 (2018).

13. Sirolli, M., Mafra, C.E.S., Santos, R.A.B.D., et al. "Influence of piezosurgery on bone healing around titanium implants: A histological study in rats", Brazilian Dental Journal, 27(3), pp. 278-283 (2016).

14. Zhang, Y., Wang, C., Zhou, S., et al. "A comparison review on orthopedic surgery using piezosurgery and conventional tools", Procedia CIRP, 65, pp. 99-104 (2017).

15. Wahlquist, S., Nelson, S., and Glivar, P. "Effect of the ultrasonic bone scalpel on blood loss during pediatric spinal deformity correction surgery", Spine Deformity, 7(4), pp. 582-587 (2019).

16. Hennet, P. "Piezoelectric bone surgery: a review of the literature and potential applications in veterinary oromaxillofacial surgery", Frontiers in Veterinary Science, 2, p. 8 (2015).

17. Vernon, D., Lobo, B.C., and Ting, J.Y. "Application of ultrasonic aspirators in rhinology and skull base surgery", Otolaryngologic Clinics of North America, 50(3), pp. 607-616 (2017).

18. Parmar, D., Mann, M., Walmsley, A.D., et al. "Cutting characteristics of ultrasonic surgical instruments", Clinical Oral Implants Research, 22(12), pp. 13851390 (2011).

19. Hollstein, S., Hoffmann, E., Vogel, J., et al. "Micromorphometrical analyses of five different ultrasonic osteotomy devices at the rabbit skull", Clinical Oral Implants Research, 23(6), pp. 713-718 (2012).

20. Lughmani, W.A., Bouazza-Marouf, K., and Ashcroft, I. "Drilling in cortical bone: a finite element model and 
experimental investigations", Journal of the Mechanical Behavior of Biomedical Materials, 42, pp. 32-42 (2015).

21. Lughmani, W.A., Bouazza-Marouf, K., and Ashcroft, I. "Finite element modeling and experimentation of bone drilling forces", Journal of Physics: Conference Series, p. 012034 (2013).

22. Gupta, V. and Pandey, P.M. "An in-vitro study of cutting force and torque during rotary ultrasonic bone drilling", Proceedings of the Institution of Mechanical Engineers, Part B: Journal of Engineering Manufacture, 232(9), pp. 1549-1560 (2018).

23. Azghandi, B.V., Kadivar, M., and Razfar, M. "An experimental study on cutting forces in ultrasonic assisted drilling", Procedia CIRP, 46, pp. 563-566 (2016).

24. Alam, K., Mitrofanov, A., Bäker, M., et al. "Stresses in ultrasonically assisted bone cutting", Journal of Physics: Conference Series, p. 012014 (2009).

25. Bai, X., Hou, S., Li, K., et al. "Experimental investigation of the temperature elevation in bone drilling using conventional and vibration-assisted methods", Medical Engineering \& Physics, 69(6), pp. 1-7 (2019).

26. Sun, Z., Wang, Y., Xu, K., et al. "Experimental investigations of drilling temperature of high-energy ultrasonically assisted bone drilling", Medical Engineering \& Physics, 65, pp. 1-7 (2019).

27. Saghafi, B., Ghoreishi, M., and Narooei, K. "Prediction of safe zone for osteonecrosis in the cutting process of bovine cortical femur bone using Arbitrary Lagrangian-Eulerian method and multi-objective optimization", The International Journal of Advanced Manufacturing Technology, 104(5-8), pp. 2031-2043 (2019).

28. Alam, K. "Experimental and numerical analysis of conventional and ultrasonically-assisted cutting of bone", Doctoral Thesis, Loughborough University (2009).

29. Ying, Z., Shu, L., and Sugita, N. "Experimental and finite element investigation of ultrasonic vibration assisted bone cutting", Proceedings of JSPE Semestrial Meeting 2019 JSPE Spring Conference, pp. 848-849 (2019).

30. Ying, Z., Shu, L., and Sugita, N. "Experimental and finite element analysis of force and temperature in ultrasonic vibration assisted bone cutting", Annals of Biomedical Engineering, 23(4), pp. 1-10 (2020).

31. Peng, Z., Zhang, D., Zhang, X., et al. "Ultrasonicassisted transducer for electrosurgical electrodes", Procedia CIRP, 89, pp. 245-249 (2020).

32. Rezaei, M., Farzin, M., Ahmadi, F., et al. "Design, analysis, and manufacturing of a bone cutting ultrasonic horn-tool and verification with experimental tests", Journal of Applied and Computational Mechanics, 5(2), pp. 1-10 (2020).

33. Wang, J., Zhang, J., Feng, P., et al. "Experimental and theoretical investigation on critical cutting force in rotary ultrasonic drilling of brittle materials and composites", International Journal of Mechanical Sciences, 135, pp. 555-564 (2018).

34. Alam, K. and Qamar, S.Z. "Ultrasonically assisted bone drilling-effect of process parameters on delamination", Materials and Manufacturing Processes, 33(16), pp. 1894-1898 (2018).

35. Ralston, S.H. "Bone structure and metabolism", Medicine, 41(10), pp. 581-585 (2013).

36. Li, S., Abdel-Wahab, A., Demirci, E., et al. "Penetration of cutting tool into cortical bone: experimental and numerical investigation of anisotropic mechanical behaviour", Journal of Biomechanics, 47(5), pp. 11171126 (2014).

37. Weerasooriya, T., Sanborn, B., Gunnarsson, C.A., et al. "Orientation dependent compressive response of human femoral cortical bone as a function of strain rate", Journal of Dynamic Behavior of Materials, 2(1), pp. 74-90 (2016).

38. Morgan, E.F., Unnikrisnan, G.U., and Hussein, A.I. "Bone mechanical properties in healthy and diseased states", Annual Review of Biomedical Engineering, 20, pp. 119-143 (2018).

39. Li, S., Demirci, E., and Silberschmidt, V.V. "Variability and anisotropy of mechanical behavior of cortical bone in tension and compression", Journal of the Mechanical Behavior of Biomedical Materials, 21, pp. 109-120 (2013).

40. Alam, K. "Direction-dependent analysis of force and torque in conventional and ultrasonically-assisted drilling of cortical bone", Scientia Iranica, Transaction B, Mechanical Engineering, 22(1), p. 258 (2015).

41. Yeager, C., Nazari, A., and Arola, D. "Machining of cortical bone: surface texture, surface integrity and cutting forces", Machining Science and Technology, 12(1), pp. 100-118 (2008).

42. Sui, J., Sugita, N., Ishii, K., et al. "Force analysis of orthogonal cutting of bovine cortical bone", Machining Science and Technology, 17(4), pp. 637-649 (2013).

43. Macbeath, A., Cardoni, A., and Luca, M. "Design of an ultrasonic blade for cutting bone", Applied Mechanics and Materials, 3(2), pp. 79-84 (2005).

44. Kazim, S.F., Enam, S.A., and Shamim, M.S. "Possible detrimental effects of neurosurgical irrigation fluids on neural tissue: an evidence based analysis of various irrigants used in contemporary neurosurgical practice", International Journal of Surgery, 8(8), pp. 586-590 (2010).

45. Myers, R.H., Montgomery, D.C., and Anderson-Cook, C.M., Response Surface Methodology: Process and Product Optimization Using Designed Experiments, John Wiley \& Sons, Hoboken, New Jersey (2016).

46. Antony, J., Design of Experiments for Engineers and Scientists, Elsevier, p. 221 (2014).

47. Eggers, G., Klein, J., Blank, J., et al. "Piezosurgery®: An ultrasound device for cutting bone and its use and 
limitations in maxillofacial surgery", British Journal of Oral and Maxillofacial Surgery, 42(5), pp. 451-453 (2004).

48. Wang, Y., Li, D.-L., Ding, Z.-J., et al. "Modeling and verifying of sawing force in ultrasonic vibration assisted diamond wire sawing (UAWS) based on impact load", International Journal of Mechanical Sciences, 164, p. 105161 (2019).

49. Shu, L. and Sugita, N. "Analysis of fracture, force, and temperature in orthogonal elliptical vibration-assisted bone cutting", Journal of the Mechanical Behavior of Biomedical Materials, 103, p. 103599 (2020).

50. Muhammad, R., Ahmed, N., Maqsood, S., et al. "Influence of tool material on forces, temperature, and surface quality of Ti-15333 alloy in CT and UAT", Scientia Iranica, 26(5), pp. 2805-2816 (2019).

51. Ahmed, N., Mitrofanov, A., Babitsky, V., et al. "Analysis of forces in ultrasonically assisted turning", Journal of Sound and Vibration, 308(3-5), pp. 845854 (2007).

52. Soriano, J., Garay, A., AristimuУo, P., et al. "Effects of rotational speed, feed rate and tool type on temperatures and cutting forces when drilling bovine cortical bone", Machining Science and Technology, 17(4), pp. 611-636 (2013).

53. Alam, K., Mitrofanov, A., and Silberschmidt, V.V. "Experimental investigations of forces and torque in conventional and ultrasonically-assisted drilling of cortical bone", Medical Engineering \& Physics, 33(2), pp. 234-239 (2011).

54. Plaskos, C., Hodgson, A.J., and Cinquin, P. "Modelling and optimization of bone-cutting forces in orthopaedic surgery", International Conference on Medical Image Computing and Computer-Assisted Intervention, pp. 254-261 (2003).

55. Lucas, M., Macbeath, A., Mcculloch, E., et al. "A finite element model for ultrasonic cutting", Ultrasonics, 44, pp. e503-e509 (2006).

56. Khambay, B. and Walmsley, A. "Investigations into the use of an ultrasonic chisel to cut bone. Part 1: forces applied by clinicians", Journal of Dentistry, 28(1), pp. 31-37 (2000).

57. Khambay, B. and Walmsley, A. "Investigations into the use of an ultrasonic chisel to cut bone. Part 2: cutting ability", Journal of Dentistry, 28(1), pp. 3944 (2000).

58. Schlee, M., Steigmann, M., Bratu, E., et al. "Piezosurgery: basics and possibilities", Implant Dentistry, 15(4), pp. 334-340 (2006).

59. Sohn, D.-S., Ahn, M.-R., Lee, W.-H., et al. "Piezoelectric osteotomy for intraoral harvesting of bone blocks", The International Journal of Periodontics \& Restorative Dentistry, 27(2), p. 127 (2007).
60. Pan, Z. "Modelling and design of ultrasonic bone cutting blades", Doctoral Thesis, College of Science and Engineering, University of Glasgow (2015).

61. Claire, S., Lea, S.C., and Walmsley, A.D. "Characterisation of bone following ultrasonic cutting", Clinical Oral Investigations, 17(3), pp. 905-912 (2013).

62. Muhammad, R. "Dynamic behaviour of $\beta$-Ti-15333 in ultrasonically assisted turning: experimental and numerical analysis", Scientia Iranica, 24(6), pp. 29042914 (2017).

\section{Biographies}

Mehdi Rezaei received his BS degree in Mechanical Engineering from Islamic Azad University Najafabad Branch in 2007 and his MSc degree in the same field from Isfahan University of Technology (IUT), Isfahan, Iran in 2011. He is currently is a Ph.D. student in Manufacturing Engineering at the Isfahan University of Technology, Isfahan, Iran. His research activities include manufacturing, ultrasonically assisted cutting and machining, finite element modelling, and biomechanics.

Mahmoud Farzin is a Professor in the Department of Mechanical Engineering, Isfahan University of Technology, Isfahan, Iran. His research mainly focuses on various manufacturing processes used in Medical applications, Metal Forming Processes such as Fine Blanking, Hydro-forming, Micro-forming as well as die design, and FEM simulations of the above-mentioned processes.

Mohammad Reza Niroomand received his BS, $\mathrm{MSc}$, and $\mathrm{PhD}$ degrees from the Department of Mechanical Engineering, Isfahan University of Technology (IUT), Isfahan, Iran, in 2004, 2006, and 2012, respectively. Since 2013, he is an Assistant Professor in the Department of Mechanical Engineering, Payame Noor University (PNU), Isfahan, Iran. His current research focuses on biomechanics, design, and analysis of experiments, rolling, optimization, and welding.

Farshid Ahmadi received his $\mathrm{PhD}$ in Mechanical Engineering from the Isfahan University of Technology (with the highest honor). He is currently an Assistant Professor in the Department of Mechanical Engineering, University of Kashan, Iran. His research is multidisciplinary and revolves around metal forming, Ultrasonic assisted manufacturing, FEM, bio-mechanics, and nanostructured materials. 